\title{
The Design of Educational Programs in System Dynamics at Worcester Polytechnic Institute (WPI) ${ }^{\dagger}$
}

\author{
Oleg V. Pavlov*, James K. Doyle, Khalid Saeed, James M. Lyneis and Michael J. Radzicki \\ Department of Social Science and Policy Studies, Worcester Polytechnic Institute, 100 Institute Rd., \\ Worcester, MA 01609, USA; E-Mails: doyle@wpi.edu (J.K.D.); saeed@wpi.edu (K.S.); \\ jmlyneis@myfairpoint.net (J.M.L.); mjradz@wpi.edu (M.J.R.) \\ $\dagger$ Based on "Doyle, J.K.; Eberlein, B.; Ford, A.; Hines, J.; Lyneis, J.M.; Parsons, K.; Pavlov, O.; \\ Radzicki, M.J.; Saeed, K.; Warren, K. Design of a Master of Science Degree Program in System \\ Dynamics at WPI. In Proceedings of the 27th International Conference of the System Dynamics \\ Society, Albuquerque, NM, USA, 26-30 July 2009". \\ * Author to whom correspondence should be addressed; E-Mail: opavlov@wpi.edu.
}

Received: 11 February 2014; in revised form: 12 March 2014 / Accepted: 19 March 2014 /

Published: 21 March 2014

\begin{abstract}
Educational programs leading to degrees in system dynamics are rare and thus of critical importance to the future of the field of system dynamics. However, to a large extent such programs have not yet been made transparent to the system dynamics community as a whole. The present article describes the design and rationale for undergraduate and graduate programs at Worcester Polytechnic Institute (WPI). The goal of the article is to invite feedback from the system dynamics community about our specific programs as well as to facilitate wider discussion about the appropriate content, design, and pedagogy of degree programs and courses in system dynamics.
\end{abstract}

Keywords: system dynamics education; computer modeling; curriculum design; academic program management

\section{Introduction}

System dynamics (SD) courses are taught at dozens of universities throughout the world. However, only a small number of institutions offer enough courses for complete degrees in system dynamics. 
In most cases, the system dynamics curriculum is part of a larger curriculum in a school of, for example, Business or Public Policy, and the primary means of educational delivery beyond a few introductory courses is research mentorship with individual system dynamics faculty. In a few cases, the system dynamics curriculum is part of a larger "system sciences" program that covers a wide variety of different modeling approaches. Those programs that offer substantial coursework in system dynamics (say, five courses or more) and a degree titled "System Dynamics" can be counted on one hand.

At the same time, there has long been interest within the system dynamics community in examining and understanding the nature and quality of university curricula in system dynamics. Certainly, the growth and well being of the field depends on the availability of high-quality education in system dynamics. Nearly twenty years ago, Barlas [1] argued that for system dynamics to be a successful discipline there need to be university educational programs that provide formal training. Not only such programs would teach the foundations of the system dynamics method, they would also ensure consistency in the interpretation of the skills and act as conduits for the latest developments in the field to be passed on to students.

However, various efforts over the years to develop curriculum guidelines have thus far not been successful. An alternative approach may be to encourage programs to voluntarily make available to others the design and rationale behind their programs, which would open them up to scrutiny and constructive criticism from peers. Thus far there has been little published literature in the system dynamics field describing the actual or recommended design, content, and pedagogy of system dynamics courses and programs (although, see, e.g., [1-6]).

The present authors believe that, given their rarity, university programs in system dynamics have a special responsibility to the field to make the content and design of their programs transparent. Thus, the purpose of the present article is to describe the development and design of degree programs in System Dynamics at Worcester Polytechnic Institute (WPI), as a way of encouraging the discussion of general issues of curriculum design. For example, how should programs in System Dynamics be structured and taught? What topics and in what sequence should be covered? What pedagogies should be emphasized? Is there a place for an undergraduate program or are graduate programs in system dynamics more appropriate? What topics beyond the field should a system dynamics student be familiar with (e.g., business, economics, psychology, mathematics)? This article does not answer all these questions, but we hope that the discussion will continue.

\section{Attributes of University Courses}

Based on the literature review and our own experience, we suggest that system dynamics courses can be characterized by several attributes, as shown in Table 1. These attributes form a convenient framework for course comparisons. We discuss some of the attributes of WPI courses in this article.

The ultimate goal of any system dynamics course - which can be part of a system dynamics program - is to teach students the system dynamics method so they can apply it to various situations. While there are many practitioners of system dynamics and courses have been taught for years, there is still no unequivocal set of skills identified and agreed upon by the system dynamics community as the skill core of the system dynamics method. Andersen and Richardson [2,7], who were two of the early authors to write about system dynamics curricula, emphasized that system dynamics training should 
methodically teach the seven stages of system dynamics modeling inquiry: problem recognition, system conceptualization, model representation, model behavior, model evaluation, policy analysis and model use. Richmond [8] groups various skills into the following sets: dynamic thinking, closed-loop thinking, generic thinking, structural thinking, operational thinking, continuum thinking and scientific thinking. Based on their experience at Delft University, Meyers et al. [5] add that communication and reporting, team and project work and academic reflection are also important skills for system dynamicists. As model development and use is an iterative process, there is a great deal of overlap and interaction between the modeling stages. The necessary skills of system dynamics can also be deduced from the content of textbooks on the subject, and there are several of them on the market.

Table 1. Attributes of a System Dynamics Course.

Skills Taught. What is exactly covered?

Target Audience. Is the course graduate, undergraduate or both? Or is it part of an executive education program?

Type Of Course. Is it a stand-alone course or is it part of a program?

Registration Requirement. Is it a mandatory or elective course?

Faculty. Do tenured/tenure-track, full time or part-time faculty teach it?

Difficulty Level. Is the course introductory or advanced?

Course Organization. Is it a dedicated system dynamics course or does the course include a system dynamics module?

Purpose. Is the purpose of the course to teach SD, or to teach something else using SD?

Course Design. Is it project based, lecture, laboratory, case-studies, simulation games?

Delivery Method. Is it online, class-based or hybrid?

Length. Is it a semester, term, short workshop, or self-paced online course?

Academic Credit, full academic credit, continuing education credit, or none

Tuition, free to high

What is an appropriate audience for a system dynamics course or a program? Barlas [1] concludes that an "undergraduate stand-alone course dedicated exclusively to system dynamics... is least common, yet most important for the growth of the field". He notes that only very few universities offer undergraduate courses in system dynamics and calls for more undergraduate education in system dynamics. A review of system dynamics courses in the U.S. reveals that most courses in system dynamics are still at the graduate level (see Appendix A). Massachusetts Institute of Technology (MIT) also offers system dynamics workshops as part of its executive education program.

The majority of available courses are stand-alone courses or they are part of a non-system dynamics program. For example, the Delft University of Technology lists two courses-Introduction to System Dynamics and Advanced System Dynamics - that are mandatory courses for one undergraduate program and one Master's program, though these programs do not grant system dynamics degrees [5]. At Portland State University, system dynamics is taught as part of the graduate program in system science. System dynamics can also be incorporated into various application or modeling courses as a module. For example, Barlas [1] integrated a system dynamics module in a mathematical modeling course.

Unless a system dynamics course or program receives external funding, to be sustainable a university has to charge tuition to recover the course delivery cost. Thanks to government funding of the educational system, the University of Bergen in Norway offers a free online course on resource 
management. On the other hand, WPI currently charges $\$ 3,843$ for a three-credit-hour graduate course, which is a typical tuition charge at a private American university. For anyone who does not require academic credit, WPI offers an audit registration option, which is half the regular tuition rate. A non-credit two-day class-based system dynamics course by isee systems costs $\$ 1200-1500$ (see [9]). A five-day online workshop by Strategy Dynamics Ltd., a U.K. company, is $£ 250$, or about $\$ 400$. A five-day executive education course at MIT is $\$ 8,100$ (see [10]).

\section{System Dynamics at WPI}

System dynamics was established at WPI by Michael Radzicki, who began teaching a two-course undergraduate sequence in system dynamics in 1990. James Doyle was recruited in 1992 to teach group model building and judgment and decision making. By 1996 Khalid Saeed had joined WPI as Head of the Department of Social Science and Policy Studies, the department that administers WPI's system dynamics programs. Soon thereafter, in 1998, Saeed, Doyle, and Radzicki established the world's first Bachelor of Science degree program in System Dynamics at WPI [11]. Professor of Practice James M. Lyneis and Elise Axelrad joined the WPI system dynamics faculty in 2001, followed by Oleg Pavlov in 2002. In 2003 WPI began offering its first graduate courses in system dynamics. Some of these courses had previously been taught as distance learning courses at MIT, and several of the faculty involved in that program (Bob Eberlein, Andy Ford, Jim Hines, and Kim Warren) were brought in as adjunct faculty to keep the courses going. By 2004 nine graduate courses as well as a five-course graduate certificate program in system dynamics had been established. The first Ph.D. student in the interdisciplinary doctorate program in system dynamics, Shelly Friedman, graduated in 2005. In 2006 the M.S. program in System Dynamics was approved by the WPI Faculty and Trustees. The first four graduates of the M.S. program were awarded their degrees in May of 2007. Table 2 summarizes the development of system dynamics programs at WPI.

Table 2. History of System Dynamics at Worcester Polytechnic Institute (WPI).

\begin{tabular}{cc}
\hline 1990 & First SD courses \\
1998 & B.S. degree program in SD \\
2003 & First graduate SD courses \\
2004 & Graduate certificate in SD \\
2005 & First Ph.D. graduate \\
2006 & M.S. degree program in SD \\
2007 & First M.S. graduates \\
\hline
\end{tabular}

\section{Program Goals}

The WPI System Dynamics teaching faculty has adopted the following mission statement for the university's programs in system dynamics:

- System dynamics is a method for understanding and changing the behavior of systems. It centers around the development and use of formal computer models that:

(1) Apply the accepted system dynamics theory of structure (endogenous behavior, positive and negative feedback loops, accumulations and delays, and representation of decision-making); 
(2) Are constructed following the scientific method (problem defined in terms of a reference mode of problem behavior, dynamic hypothesis as a theory of that behavior, formal computer model of the hypothesis, testing of the model/hypothesis against data, extensive analysis, and policy design); and

(3) Use best practice tools and techniques (system dynamics software, units checking, standard formulations, generic models and building blocks, graphical functions, etc.).

- These three components collectively define rigorous system dynamics. Further, in real world applications:

(4) Models should be developed so as to achieve client confidence and acceptance (using various approaches including "group model building")

(5) Model development must be taught in the context of the application field.

\section{Program Design}

WPI is the only institution in the U.S. that offers complete educational programs that lead to the B.S. in System Dynamics, Graduate Certificate, M.S., and Ph.D. degrees in System Dynamics (Figure 1). WPI currently offers 11 online semester-long graduate system dynamics courses (see [12]) that are also open to advanced undergraduate students. For the benefit of the undergraduate program, there are also two undergraduate class-based system dynamics courses and two project-based courses. System dynamics courses can be taken as an elective by WPI Economics majors. Additionally, system dynamics has been incorporated into various undergraduate economics courses.

The online program also acts as a hub that connects professionals and scientists with system dynamics experts, thus forming a community of practice. The interaction, which is important for building such a community of practice, is facilitated through WPI-sponsored online discussion boards, online sessions with instructors, and an active online group in LinkedIn called "WPI System Dynamics" which was established several years ago. The online LinkedIn group currently has 214 members at different levels of SD expertise.

The academic component of the online program is overseen by the Department of Social Science and Policy Studies. However, the administrative elements (enrollment, marketing, and online delivery) are managed by the Corporate and Professional Education (CPE) division at WPI, which has been an integral part of this university for nearly 30 years. All existing CPE programs are financially self-sufficient.

Below we provide more information on WPI programs. It should be noted that WPI follows separate academic schedules and uses different academic credit systems for its undergraduate and graduate programs. Undergraduate programs follow a term calendar, while graduate programs follow a semester calendar. Also, an undergraduate course is worth $1 / 3$ unit. So the system dynamics requirement of $5 / 3$ units means five undergraduate courses in system dynamics. A graduate course is counted as 3 credit hours. The Masters degree in SD requires 30 credit hours, or 10 graduate-level courses. 
Figure 1. A Tiered Learning Levels view of skills and matching education programs in system dynamics at WPI. The courses, workshops and projects that are mentioned in the figure are on system dynamics.

Learning Levels

\section{Expert}

Create Theory with Models, Link to Other Disciplines, Estimation and Optimization, Advance Methodology of SD, Lead Projects, Teach All Levels

\section{Advanced}

Create Insight Simulation Models, Maintain Calibrated Models, Facilitate Group Modeling, Ability to Communicate About Models, Validation, Teach Lower Levels

\section{Practitioner}

Define a Problem, Draw Reference Modes, Create Complex Causal Loop Diagrams, General Structures, Archetypes, Maintain Insight Models, Some Basic Validation

\section{Participant Awareness}

Able to Create Simple Causal Loop Diagrams, Basic Stock-and-Flow, Run Simulation, How to Contribute to a Group Model Building Event

\section{General Awareness}

Understand terminology, Systems Thinking
Programs at WPI

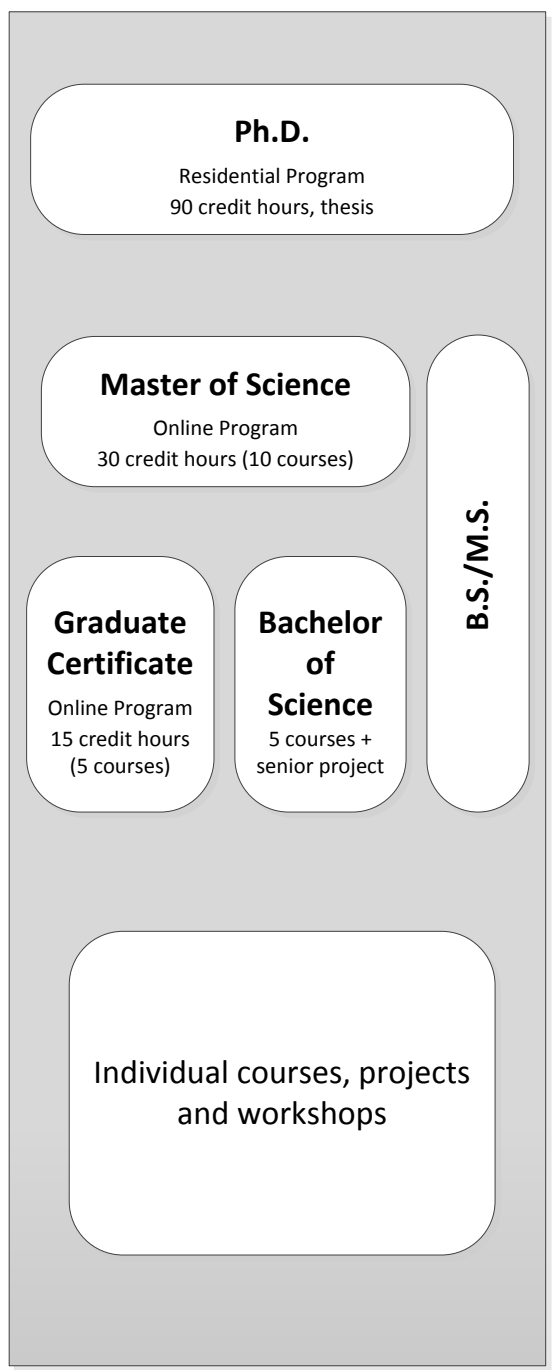

\subsection{Bachelor of Science in System Dynamics}

Tables 3 and 4 explain the learning outcomes and distribution requirements for the Bachelor of Science in System Dynamics.

\subsection{Master of Science Degree in System Dynamics}

WPI's M.S. program in system dynamics was the culmination of more than a decade of strategic planning and curriculum development on the part of several faculty. Students are required to complete 30 credit hours (10 courses). At least 21 of these credit hours ( 7 courses) must be in system dynamics. The remaining 9 credit hours may be taken in mathematics, management, economics, or additional system dynamics courses. Six of these 9 credit hours may also be supervised research. Table 5 shows course requirements for the M.S. in system dynamics (full course descriptions appear in Appendix B). 
Table 3. Learning Outcomes of the System Dynamics Major.

1. Ability to recognize the dynamic patterns of behavior in real-world data.

2. Ability to formulate feedback hypotheses representing problems and understand the hypotheses' logic.

3. Ability to translate feedback hypotheses into stock and flow models.

4. Ability to experiment with stock and flow models in order to establish their fidelity.

5. Ability to design experiments with a stock and flow model, implement them, and interpret their results, in order to arrive at effective solutions that address the defined problems of a system dynamics project.

6. Literacy in the technical aspects of problems in the student's area of application.

7. Ability to communicate effectively the results of a system dynamics analysis in speech and writing.
8. An understanding of basic concepts in software programming and management science.

9. An understanding of how to apply scientific principles in system dynamics modeling.

10. Ability to develop, organize, manage, and successfully conduct a significant system dynamics project.

11. Ability to locate and integrate valid and appropriate information from multiple fields and perspectives for use in systems dynamics models.

12. An understanding of the endogenous causes of societal problems.

13. An appreciation of the inter-connectedness between technology, society, and the environment.

14. Ability to form and work effectively in groups involving system dynamics modelers, appropriate domain experts, and stakeholders.

Source: WPI Undergraduate Catalog 2013-14.

Table 4. Program Distribution Requirements for the Bachelor's Degree in System Dynamics.

The normal period of residency at WPI is 16 terms. In addition to the WPI requirements applicable to all students, completion of a minimum of 10 units of study is required in system dynamics, social science, basic science, and mathematics, and computer science as follows:

\section{SYSTEM DYNAMICS}

\section{REQUIREMENTS}

1. System Dynamics (Note 1)

2. Other Social Science (Note 2)

3. Business (Note 3)

4. Mathematics/basic sciences/engineering (Note 4)

5. Computer Science (Note 5)

6. Application Area (Note 6)

7. MQP

\section{NOTES:}

1. Only social science courses with a "5" in the second digit of the course number count toward the system dynamics requirement.

2. Must include microeconomics or macroeconomics, cognitive or social psychology, and public policy.

3. Must include organizational science.

4. Must include differential and integral calculus, differential equations, and numerical or statistical analysis.

5. Courses on computer programming and programming languages are recommended.

6. This requirement is satisfied by a cohesive set of work from the fields of social science, management, science, mathematics, computer science, or engineering as specified in the curriculum the guidelines for system dynamics major. 
Table 5. Course requirements for the M.S. in system dynamics.

1. Foundation courses, required courses (6 credits)

SD 550 System Dynamics Foundation: Managing Complexity

SD 551 Modeling and Experimental Analysis of Complex Problems

2. Methodological courses, two or three courses ( 6 to 9 credits) from the following courses:

SD 552 System Dynamics for Insight

SD 553 Model Analysis and Evaluation Techniques

SD 554 Real World System Dynamics

SD 556 Strategic Modeling and Business Dynamics

SD 557 Latent Structures, Unintended Consequences, and Public Policy

3. Application courses, three or four courses ( 9 to 12 credits) from the following courses:

SD 560 Strategy Dynamics

SD 561 Environmental Dynamics

SD 562 Project Dynamics

SD 565 Macroeconomic Dynamics

4. Electives, one to three courses (3 to 9 credits) from the following or additional courses from the previous lists:

SD 590 Special Topics in System Dynamics (credit as specified)

Graduate independent study courses in System Dynamics (credit as specified)

MA 510/CS522 Numerical Methods

MA 512 Numerical Differential Equations

Approved graduate coursework in an application area (e.g., economics, psychology, management, engineering, or applied sciences)

Source: WPI Undergraduate Catalog 2013-14.

SD550 serves as our basic introductory modeling course and is a prerequisite to all other courses in the program. SD551 serves as an advanced modeling course-it covers more advanced skills and more challenging and more open-ended modeling assignments. SD550 and SD551 serve as prerequisites for most of the advanced methodology courses.

Methodological courses, as opposed to application courses, develop important basic skills in greater detail than is possible in the introductory courses. SD552 is designed to build students' modeling skills by increasing their ability to identify and adapt generic structures. SD553 covers basic topics in model evaluation and analysis, including use of subscripts, achieving and testing for robustness, use of numerical data, sensitivity analysis, and optimization/calibration of models. SD554 in many ways serves as a "capstone" course for the program. In this course students, under the direction of an experienced system dynamics consultant, work throughout the term on a consulting project in their own organization that they design and implement from start to finish.

Application courses are advanced topical courses that focus on the application of system dynamics in a particular domain of inquiry. Elective courses allow students the flexibility to take more system dynamics courses, explore new topics through one-on-one collaboration with a faculty member, improve their math skills, or develop expertise in an application area of system dynamics. Up to 6 credit hours can be Directed Research. This requirement allows students to undertake an optional Master's Thesis. 


\subsection{Graduate Certificate in System Dynamics}

A Graduate Certificate program requires 15 credit hours of graduate study (5 courses). Students take one or both of our Foundation Courses (SD550 and SD551), and complete the rest of the credits by taking a variety of methodological and application courses in system dynamics.

\subsection{B.S./M.S. in System Dynamics}

Undergraduate students can pursue a 5-year combined Bachelor's/Master's degree, in which the Bachelor's degree is awarded in any major offered at WPI and the Masters degree is awarded in System Dynamics. For this program, WPI allows the double counting of up to four courses.

\subsection{Interdisciplinary Master's Degree in Systems Modeling}

The departments of Mathematical Sciences and Social Science and Policy Studies offer an interdisciplinary Master's degree in systems modeling. The program requires 30 credit hours (10 courses) in Mathematics, System Dynamics, and electives taught in engineering, science and management departments. Students entering the program must have a Bachelor's degree, which is typically in science or engineering. Students complete 15 credit hours in system dynamics and 15 credit hours in mathematical modeling and an applications area (e.g., industrial engineering, management, infrastructure planning, telecommunications planning, and power systems). Up to 6 credit hours may be done as a supervised project which allows for an optional Master's Thesis.

\subsection{Interdisciplinary Doctorate in System Dynamics}

Social Science and Policy Studies collaborates with other departments to offer an interdisciplinary doctoral program in System Dynamics. Each program of study requires at least 60 credit hours of study and is adapted to the interests of the student and the interests of the participating faculty. A typical doctoral committee consists of three or more faculty members from participating departments.

\section{Delivery Methods}

Undergraduate system dynamics courses are delivered in the traditional classroom-based format. To allow for broader geographic reach, convenience and accessibility than class-based courses, WPI's graduate courses in system dynamics are implemented exclusively in a distance learning format through WPI's Division of Corporate and Professional Education (CPE). There are no classroom sections of the courses. They are delivered in an online asynchronous format through WPI's web-based course delivery system, myWPI, powered by the Blackboard Learning Management System. Teaching courses online reduces the cost to students as they do not incur additional expenses for travel, lodging and meals as would be required for a residential course.

Graduate online courses are taught on the same semester schedule as WPI's graduate classroom courses and students receive regular deadlines for completion of homework assignments and other tasks. The courses are just as challenging as classroom courses at WPI, often requiring 15-20 h per week of effort or more from students. Course lectures (as streaming video files) and supporting 
materials such as Power Point files are posted to myWPI. As in a classroom course, students receive detailed and timely feedback on their work. Faculty-student and student-student interaction takes place primarily via electronic discussion boards and email. WPI's distance learning students are full members of the WPI community and have electronic access to all services available to on-campus students (e.g., library, bookstore, and technical help). Instructors can choose to record the lectures at their individual computers using commonly available video recording software such as Camtasia or tape lectures at the WPI's Academic Technology Center (ATC).

Distance learning poses a unique set of challenges. The absence of face-to-face personal contact among students and faculty can potentially be a serious impediment to learning, especially for students who favor in person interactions. At WPI, we attempt to use technology to emulate the classroom experience. Below are a few solutions that we have adopted and which seem to be working well for us.

(1) Talking head: Most of the lectures are recorded and professionally edited in a studio on campus in such a way that videos show not only slides and demonstrations of computer models but also the image of the instructor superimposed on top of the slides as the talking head.

(2) Discussion board: Instructors may dedicate a sizable part of the grade to discourse on the discussion board. The discussion board tool is integrated with Blackboard. If the online discussions slow down, instructors may stimulate lackluster exchanges with challenging questions.

(3) Synching the class: There is potentially a danger of losing class focus and the relevance of discussions to the syllabus of a course in the asynchronous format that we choose to follow in view of the many time zones involved and the fact that our students often need flexibility due to other commitments. We overcome this problem by not posting lessons all at once but revealing them according to a fixed schedule so students work on the same materials during the week assigned to a lesson. Assigning high penalties for late homework submissions also encourages students to observe the lesson schedule of a course. These measures greatly help create synchronism in our otherwise asynchronous classes.

(4) Virtual office hours: Though not every instructor uses them, the option of virtual office hours is available with Adobe Connect, which is a video-conferencing tool integrated with Blackboard. Based on student course evaluations, certain types of students are particularly appreciative of the life interaction.

Since developing online materials is rather time consuming, frequently revising and updating courses remains a challenge. We have discovered that the best strategy for keeping the curricula current is to do revisions gradually rather than revamping an entire course all at once. From the program management perspective, counting time spent on course maintenance towards the faculty load creates strong incentives for the faculty to keep on-line courses vibrant and up-to-date.

\section{Students}

WPI is a technological university, but it recognizes the importance of the humanities, arts and social sciences in its undergraduate curriculum, and therefore all undergraduate students must complete two social science courses before they graduate. The system dynamics courses are open to all students in the university and since they are housed in the Department of Social Science and Policy Studies, any 
system dynamics course is counted towards the social science requirement. This helps with the enrollment in the undergraduate system dynamics courses.

The students enrolled in WPI's graduate system dynamics programs are primarily mid-career professionals who enroll in courses part-time. They are not necessarily looking for a brand new career, but for the most part want to do their current job better by incorporating the tools and techniques of system dynamics. More than half of the students are above the age of 35 . The students are widely geographically dispersed around the U.S. and the world, with only about $15 \%$ residing in WPI's home state of Massachusetts. Our student body as a whole is already highly educated. Many students in graduate system dynamics courses have advanced degrees in other fields (e.g., M.B.A., M.D., M.S. in Engineering, Ph.D.). We also offer graduate SD courses which are taught on-site at various companies around New England as part of a corporate education program leading to the Certificate or the Master's degree in Systems Engineering.

Some students in graduate courses are researchers who see the systems thinking paradigm coupled with the power of system dynamics modeling as the intellectual and methodological foundation of their desire to extend beyond the limited modes of inquiry of traditional disciplines. Established researchers may take a course to acquaint themselves with the system dynamics methodology and its applications. Some of our students are researchers who already have a good understanding of traditional fields of inquiry but might need to acquire only sufficient understanding of system dynamics to draw new ideas and methodology into their work. After taking one or two courses, while maintaining a foothold in their traditional first disciplines, these researches are able to understand system dynamics sufficiently to communicate and collaborate with expert modelers.

Enrollment in system dynamics courses at WPI is shown in Table 6. It should be noted that in addition to our primary population of part-time M.S. students, a small number of B.S./M.S. and interdisciplinary Ph.D. students also register for graduate online courses.

Table 6. Enrollment in System Dynamics Courses at WPI.

\begin{tabular}{ccccc}
\hline & \multicolumn{2}{c}{ Undergraduate } & \multicolumn{2}{c}{ Graduate } \\
\hline Academic year & Sections & Enrollment & Sections & Enrollment \\
\hline $1998-99$ & 2 & 12 & N.A. & N.A. \\
$1999-00$ & 5 & 119 & N.A. & N.A. \\
$2000-01$ & 5 & 141 & N.A. & N.A. \\
$2001-02$ & 5 & 71 & N.A. & N.A. \\
$2002-03$ & 3 & 78 & N.A. & N.A. \\
$2003-04$ & 5 & 95 & 8 & 99 \\
$2004-05$ & 4 & 107 & 10 & 91 \\
$2005-06$ & 4 & 86 & 7 & 97 \\
$2006-07$ & 3 & 93 & 10 & 101 \\
$2007-08$ & 5 & 109 & 8 & 107 \\
$2008-09$ & 3 & 87 & 9 & 91 \\
$2009-10$ & 3 & 65 & 14 & 117 \\
$2010-11$ & 2 & 42 & 12 & 85 \\
$2011-12$ & 3 & 55 & 9 & 70 \\
$2012-13$ & 2 & 64 & 11 & 76 \\
\hline
\end{tabular}




\section{Faculty}

There are currently three full-time tenured faculty in Social Science and Policy Studies at WPI who teach in the system dynamics programs. In addition, there are six adjunct faculty who regularly teach online courses. WPI has been fortunate in being able to draw on the talents of system dynamics experts from around the world for its programs. Collectively, the system dynamics teaching faculty bring a wealth of experience and expertise to the program, and include three winners of the Jay Forrester Award as well as five past Presidents of the International System Dynamics Society. The list of faculty and their research interests appear in Appendix C.

\section{Course Design}

The System Dynamics courses at WPI emphasize building modeling skills through homework assignments that receive prompt and detailed feedback from the instructor. Variations in approach and emphasis are encouraged in the belief that students benefit from learning why and how diverse faculty may approach a given problem or topic differently. In all of our modeling courses students gain hands-on experience with reference modes, hypothesis formulation using causal and stock-flow diagrams, equation-writing, and model analysis. We believe that lasting, generalizable learning is best obtained by returning to the same topics again and again, with different instructors, in different courses, while studying different problem domains. Our goal is to turn students into experienced modelers who, upon graduation, will be able to manage a modeling project in a real organization from start to finish.

Table 7. System Dynamics skills taught in SD550.

\begin{tabular}{|c|c|c|}
\hline System Dynamics as a theory of behavior & Scientific modeling process & Tools and tricks \\
\hline $\begin{array}{ll}\text { - } & \text { Policy Resistance/Unintended Consequences } \\
\text { - } & \text { Fundamental Behavior Patterns } \\
\text { - } & \text { Causes of dynamic behavior: feedback and } \\
\text { - } & \text { Bascumulation } \\
\text { - } & \text { limits, fixes that fail, shifting burden) } \\
\text { - } & \text { First-order positive systems (analytical } \\
\text { - } & \text { Draining processes, Goal-gap } \\
\text { - } & \text { Exponential average } \\
\text { - } & \text { First-order system with inflow and outflow } \\
\text { - } & \text { (all linear) } \\
\text { - } & \text { Overshaped Growth (carrying capacity) } \\
\text { - } & \text { Growth feedbacks from Sterman Ch. } 10 \\
\text { - } & \text { Product Diffusion Model } \\
\text { - } & \text { Stock Mandemic (SI and SIR) } \\
\text { - } & \text { Material Delays (1st, 3rd, 6th, pipeline) } \\
\text { - } & \text { Second-order systems and oscillations (role } \\
\text { of minor and major loops) }\end{array}$ & $\begin{array}{l}\text { - System Dynamics "Standard } \\
\text { Method": conceptualization } \\
\text { (problem definition, dynamic } \\
\text { hypothesis), formulation (model } \\
\text { construction, testing, validation), } \\
\text { use (testing and understanding, } \\
\text { policy design) } \\
\text { Conceptualization exercise- } \\
\text { Peer-to-Peer } \\
\text { Modeling and policy design } \\
\text { exercise-Tragedy of } \\
\text { Commons/Fishbanks (formulation } \\
\text { including carrying capacity, } \\
\text { graphical function, first-order stock } \\
\text { control, analysis of each loop's } \\
\text { parameter sensitivity, policy design } \\
\text { focused on info from system and } \\
\text { when action needs to be taken) } \\
\text { Material delays exercise (relative } \\
\text { peaks of inflows, outflows, stock; } \\
\text { equilibrium; distribution relative to } \\
\text { average) } \\
\text { A business case exercise }\end{array}$ & $\begin{array}{ll}\text { - } & \text { Vensim } \\
\text { - } & \text { Causal-loop diagramming } \\
\text { - } & \text { linkics and conventions, } \\
\text { - } & \text { Problems with CLDs } \\
\text { - } & \text { Grock-flow diagrams (as } \\
\text { - } & \text { Calculating equilibrium and } \\
\text { - } & \text { setting up model in } \\
\text { - } & \text { Graphits checking } \\
\text { - } & \text { (normalizal Functions } \\
\text { - } & \text { Test inputs (step, pulse, cycle, } \\
& \text { ramp, exponential, noise) } \\
\text { - } & \text { Sensitivity testing } \\
\text { - } & \text { Loop knockout }\end{array}$ \\
\hline
\end{tabular}


Rather than focus on the topics a course covers, when we design (and redesign) courses, we place more emphasis on skill achievement. Each lecture, assignment, or activity is considered in relation to the general "skill" categories described in our mission statement. These "skill grids" help instructors plan their courses and help them keep track of what other instructors are doing. They also allow us a high-level view of the entire program, which helps us assess the amount of overlap and redundancy across courses (while keeping in mind that a certain degree of redundancy is desirable) as well as to identify important omissions in our program.

Table 7 provides an example of a skill grid for our introductory course, SD550. It constitutes a statement of what we think is important to include in an introductory system dynamics course, with an emphasis on skills taught in various goal categories versus the traditional linear format of a course syllabus. This list of topics is comparable to the list in an introductory system dynamics course described in Barlas [1].

\section{Conclusion}

In this article we have tried to give an overview, in some detail, of the design and rationale for our degree programs in system dynamics. We hope that by sharing this information about our program, we will obtain feedback from the system dynamics community about what we are doing wrong and perhaps, occasionally, feedback on what we are doing right. We also hope to encourage the field of system dynamics to more fully and collectively address the question of what a graduate of a system dynamics program should know and be able to do and how best to achieve those goals. In addition, we hope that by sharing our experience, other universities will be encouraged to travel down the long and difficult path of turning a few system dynamics courses into a substantial degree program.

While the usual discussion about online education revolves around the quality of online courses, creating and managing online programs brings forth a host of issues that are typically not of serious concern in class-based instruction. For distance education to work, the university must be able and willing commit significant additional resources besides the instructor's time to such programs. Creating an online program requires facilities and staff for videotaping and editing lectures as well as handling email and phone communication with students. Such a mundane task as registering for a course might suddenly turn into an ordeal and a flurry of frantic emails when students have to figure out the registration process remotely. Therefore, it is essential for an online program to have dedicated, patient and well-trained staff who can provide administrative support to the program on a day-to-day basis.

This article is not a comprehensive review of program design. We did not address resource requirements and the financial side of running a program. We did not cover many agency issues. For example, we did not discuss how to convince university administration of the viability of a program and how to reach an agreement with them about cost and revenue sharing. Also, we did not cover the issues of student and faculty recruitment in the context of managing instructional capacity in the competitive marketplace that higher education has become.

\section{Acknowledgments}

The authors would like to thank members of the system dynamics faculty at WPI for their collegiality and support. In addition, the authors would like to acknowledge the important role played 
by Pam Shelley and Diane Poirier in guiding the development and operations of the system dynamics programs and making sure they meet the needs of our students. Pam Shelley is an Associate Director of Marketing and Diane Poirier is an Associate Operations Manager within the WPI's division of Corporate and Professional Education.

\section{Author Contributions}

The article is based on the collective experience of all authors who have developed the system dynamics program at Worcester Polytechnic Institute and have been teaching in it for many years. They contributed and commented on this manuscript at all stages.

\section{Conflicts of Interest}

The authors declare no conflict of interest.

\section{References}

1. Barlas, Y. Formal System Dynamics Education in Universities. In Proceedings of the 1993 International System Dynamics Conference, Cancun, Mexico, July 1993.

2. Andersen, D.; Richardson, G.P. Toward a pedagogy of system dynamics. TIMS Stud. Manage. Sci. 1980, 14, 91-106.

3. Barlas, Y. Academics of system dynamics: It's core definition, topics, and terminology. Int. J. Pol. Model. 1995, 7, 1-15.

4. Hovmand, P.S.; O’Sullivan, J.A. Lessons from an interdisciplinary system dynamics course. Syst. Dyn. Rev. 2009, 24, 479-488.

5. Meyers, W.; Slinger, J.; Pruyt, E.; Yucel, G.; van Daalen, C. Essential Skills for System Dynamics Practitioners: A Delft University of Technology Perspective. In Proceedings of the 28th International Conference of the System Dynamics Society, Seoul, Korea, 25-29 July 2010.

6. Clauset, K.H., Jr. Notes on the teaching of system dynamics. Syst. Dyn. Rev. 1985, 1, 123-125.

7. Andersen, D.F.; Richardson, G.P. A Core Curriculum in System Dynamics. In Occasional Papers in Public Affairs; Graduate School of Public Affairs, SUNY-Albany: Albany, NY, USA, 1978.

8. Richmond, B.M. Systems thinking: Critical thinking skills for the 1990s and beyond. Syst. Dyn. Rev. 1993, 9, 113-133.

9. Intermediate Dynamic Modeling with STELLA and iThink. Available online: http://www. iseesystems.com/store/Training/InterDynamicModelingIthink.aspx (accessed on 11 February 2014).

10. Business Dynamics: MIT's Approach to Diagnosing and Solving Complex Business Problems. Available online: http://executive.mit.edu/openenrollment/program/business_dynamics_mits_ approach_to_diagnosing_and_solving_complex_business_problems/5 (accessed on 11 February 2014).

11. Doyle, J.K.; Grabowski, M.W.; Kao, A.H.; Radzicki, M.J.; Rissmiller, K.J.; Saeed, K. A Bachelor of Science Degree Program in System Dynamics at WPI. 1998. Available online: http://www. systemdynamics.org/conferences/1998/PROCEED/00005.PDF (accessed on 11 February 2014).

12. Online Master of Science. Available online: http://cpe.wpi.edu/online/sd-master.html (accessed on 11 February 2014). 


\section{Appendix A}

Table A1. A Sample of Courses in System Dynamics in the U.S. Universities, WPI Excluded.

\begin{tabular}{|c|c|c|c|}
\hline University/Courses & Location & Undergraduate & Graduate \\
\hline California State University, Chico & Chico, CA & & \\
\hline Applied Strategic Decision Making & & • & \\
\hline Business Dynamics & & • & • \\
\hline Seminar in Strategic Management and Administrative Policy & & & • \\
\hline Canisius College & Buffalo, NY & & \\
\hline Sustainability \& System Dynamics & & • & • \\
\hline Central Connecticut State University & New Britain, CT & & \\
\hline Management Systems & & • & \\
\hline James Madison University & Harrisonburg, VA & & \\
\hline System Dynamics Modeling, Simulation, and Analysis & & • & \\
\hline Introduction to System Dynamics & & & • \\
\hline System Dynamics II: Advanced Model Building and Validation & & & • \\
\hline Massachusetts Institute of Technology & Cambridge, MA & & \\
\hline Introduction to System Dynamics & & • & • \\
\hline System Dynamics for Business Policy & & • & • \\
\hline Applications of Systems Dynamics & & & • \\
\hline Doctoral Seminar in Systems Dynamics & & & • \\
\hline System Dynamics II & & & • \\
\hline Portland State University & Portland, OR & & \\
\hline System Dynamics & & & • \\
\hline Texas A\&M University & College Station, TX & & \\
\hline Strategic Construction and Engineering Management & & & • \\
\hline University at Albany, Public Administration and Policy Department & Albany, NY & & \\
\hline Introduction to System Dynamics & & • & \\
\hline Data, Models, and Decisions I (contains a module on system dynamics) & & & • \\
\hline $\begin{array}{l}\text { System Thinking and Strategic Management (contains qualitative system } \\
\text { dynamics }\end{array}$ & & & • \\
\hline Business Dynamics: Simulation Modeling for Decision-Making & & & • \\
\hline Simulation for Policy Analysis and Design & & & • \\
\hline Advanced Topics in System Dynamics & & & • \\
\hline University of Houston & Houston, TX & & \\
\hline Systems Thinking & & & • \\
\hline University of Southern Maine & Portland, ME & & \\
\hline Special Topics in Management: Introduction to System Dynamics & & & • \\
\hline University of Utah & Salt Lake City, UT & & \\
\hline System Dynamics and Environmental Policy & & & • \\
\hline Complexity and Systems Thinking & & & • \\
\hline University of Washington & Seattle, WA & & \\
\hline Information Dynamics I & & & • \\
\hline Virginia Tech & Blacksburg, VA & & - \\
\hline Applied Systems Engineering (Systems Thinking and Modeling) & & & • \\
\hline Advanced Dynamic Modeling & & & \\
\hline Washington State University & Pullman, WA & & \\
\hline Modeling the Environment & & • & \\
\hline System Dynamic Models of Environmental Systems & & & • \\
\hline Washington University in St. Louis & St. Louis, MO & & \\
\hline $\begin{array}{l}\text { A system Dynamics Approach to Designing Sustainable Social Policies and } \\
\text { Programs }\end{array}$ & & & • \\
\hline Special Topics: Group Model Building & Salem, OR & & \\
\hline Willamette University & & & • \\
\hline Business Dynamics: Systems Thinking and Modeling for a Complex World & & & - \\
\hline
\end{tabular}

Sources: University websites; System Dynamics Society. Last accessed: 5 November 2013. 


\section{Appendix B: WPI Graduate Courses in System Dynamics}

\section{SD 550. System Dynamics Foundation: Managing Complexity}

Why do some businesses grow while others stagnate or decline? What causes oscillation and amplification - the so called "bullwhip" - in supply chains? Why do large scale projects so commonly over overrun their budgets and schedules? This course explores the counter-intuitive dynamics of complex organizations and how managers can make the difference between success and failure. Students learn how even small changes in organizational structure can produce dramatic changes in organizational behavior. Real cases and computer simulation modeling combine for an in-depth examination of the feedback concept in complex systems. Topics include: supply chain dynamics, project dynamics, commodity cycles, new product diffusion, and business growth and decline. The emphasis throughout is on the unifying concepts of system dynamics.

\section{SD 551. Modeling and Experimental Analysis of Complex Problems}

This course deals with the hands on detail related to analysis of complex problems and design of policy for change through building models and experimenting with them. Topics covered include: slicing complex problems and constructing reference modes; going from a dynamic hypothesis to a formal model and organization of complex models; specification of parameters and graphical functions; experimentations for model understanding, confidence building, policy design and policy implementation. Modeling examples will draw largely from public policy agendas. Prerequisites: SD 550 System Dynamics Foundation: Managing Complexity

\section{SD 552. System Dynamics for Insight}

The objective of this course is to help students appreciate and master system dynamics' unique way of using of computer simulation models. The course provides tools and approaches for building and learning from models. The course covers the use of molecules of system dynamics structure to increase model building speed and reliability. In addition, the course covers recently developed eigenvalue-based techniques for analyzing models as well as more traditional approaches. Prerequisites: SD 550 System Dynamics Foundation: Managing Complexity and SD 551 Modeling and Experimental Analysis of Complex Problems

\section{SD 553. Model Analysis and Evaluation Techniques}

This course focuses on analysis of models rather than conceptualization and model development.

It provides techniques for exercising models, improving their quality and gaining added insights into what models have to say about a problem. Five major topics are covered: use of subscripts, achieving and testing for robustness, use of numerical data, sensitivity analysis, and optimization/ calibration of models. The subscripts discussion provides techniques for dealing with detail complexity by changing model equations but not adding additional feedback structure. Robust models are achieved by using good individual equation formulations and making sure that they work together well though automated behavioral experiments. Data, especially time series data, are fundamental to finding 
and fixing shortcomings in model formulations. Sensitivity simulations expose the full range of behavior that a model can exhibit. Finally, the biggest section, dealing with optimization and calibration of models develops techniques for both testing models against data and developing policies to achieve specified goals. Though a number of statistical issues are touched upon during the course, only a basic knowledge of statistics and statistical hypothesis testing is required. Prerequisites: SD 550 System Dynamics Foundation: Managing Complexity and SD 551 Modeling and Experimental Analysis of Complex Problems, or permission of the instructor.

\section{SD 554. Real World System Dynamics}

In this course students tackle real-world issues working with real managers on their most pressing concerns. Many students choose to work on issues in their own organizations. Other students have select from a number of proposals put forward by managers from a variety of companies seeking a system dynamics approach to important issues. Students experience the joys (and frustrations) of helping people figure out how to better manage their organizations via system dynamics. Accordingly the course covers two important areas: consulting (i.e., helping managers) and the system dynamics standard method - a sequence of steps leading from a fuzzy "issue area" through increasing clarity and ultimately to solution recommendations. The course provides clear project pacing and lots of support from the instructors and fellow students. It is recommend that students take SD 554 Real World System Dynamics toward the end of their system dynamics coursework as it provides a natural transition from coursework to system dynamics practice. Prerequisites: SD 550 System Dynamics Foundation: Managing Complexity and SD 551 Modeling and Experimental Analysis of Complex Problems

\section{SD 556. Strategic Modeling and Business Dynamics}

The performance of firms and industries over time rarely unfolds in the way management teams expect or intend. The purpose of strategic modeling and business dynamics is to investigate dynamic complexity by better understanding how the parts of an enterprise operate, fit together and interact. By modeling and simulating the relationships among the parts we can anticipate potential problems, avoid strategic pitfalls and take steps to improve performance. We study a variety of business applications covering topics such as cyclicality in manufacturing, market growth and capital investment. The models are deliberately small and concise so their structure and formulations can be presented in full and used to illustrate principles of model conceptualization, equation formulation and simulation analysis. We also review some larger models that arose from real-world applications including airlines, the oil industry, the chemicals industry and fast moving consumer goods. Students work with selected business policy problems based on generic structures discussed in the lessons. Prerequisite: SD 550 System Dynamics Foundation: Managing Complexity

\section{SD 557. Latent Structures, Unintended Consequences, and Public Policy}

This course addresses policy resilience and unintended consequences arising out of actions that are not cognizant of the latent structure causing the problem. An attempt is made to identify the generic systems describing such latent structures. The latent structures discussed include a selection from 
capacity constraining and capacity enabling systems, resource allocation, and economic cycles of various periodicities. Problems discussed in lessons include pests, gang violence, terrorism, political instability, professional competence in organizations, urban decay, and economic growth and recessions. Students work with selected public policy problems relevant to the generic latent structures discussed in the course. Pre-requisites: SD 550 System Dynamics Foundation: Managing Complexity, SD 551 Modeling and Experimental Analysis of Complex Problems

\section{SD 558. Introduction to Agent-Based Modeling}

The purpose of this course is to provide students with an introduction to the field of agent-based computer simulation modeling in the social sciences. The course begins with an outline of the history of the field, as well as of the similarities and differences between agent-based computer simulation modeling and system dynamics computer simulation modeling. An important goal of the course is to provide students with guidelines for deciding when it is preferable to apply agent-based modeling, and when it is preferable to apply system dynamics modeling, to a particular problem. Through a series of example models and homework exercises students are introduced to the software that is used in the course. Generally speaking, as the course progresses students will be introduced to increasingly complicated agent-based models and exercises so that their modeling skills will grow. The goal is to increase students' modeling skills so that they will eventually be able to create their own agent-based models from scratch. The remainder of the course is devoted to examining models of socioeconomic phenomena that reside within two broad categories of agent-based models: cellular automata models and multi-agent models. Along the way the cross-category, cross-disciplinary, principles of agent-based modeling (micro-level agents following simple rules leading to macro-level complexity, adaptation, evolving structure, emergence, non-ergodicity) are emphasized.

\section{SD 560. Strategy Dynamics}

This course provides a rigorous set of frameworks for designing a practical path to improve performance, both in business and non-commercial organizations. The method builds on existing strategy concepts, but moves substantially beyond them, by using the system dynamics method to understand and direct performance through time. Topics covered include: strategy, performance and resources; resources and accumulation; the 'Strategic Architecture'; resource development; rivalry and the dynamics of competition; strategy, policy and information feedback; resource attributes; intangible resources; strategy, capabilities and organization; industry dynamics and scenarios. Case studies and models are assigned to students for analysis. Prerequisite: SD 550 System Dynamics Foundation: Managing Complexity or permission of the instructor.

\section{SD 561. Environmental Dynamics}

Environmental Dynamics introduces the system dynamics students to the application in environmental systems. The course materials include the book Modeling the Environment, a supporting website, lectures and the corresponding power point files. Students learn system dynamics with examples implemented with the Stella software. The course includes a variety of small models and 
case applications to watershed management, salmon restoration, and incentives for electric vehicles to reduce urban air pollution The students conclude the course with a class project to improve one of the models from the text. The improvements may be implemented with either the Stella or the Vensim software. Prerequisite: SD 550 System Dynamics Foundation: Managing Complexity.

\section{SD 562. Project Dynamics}

This course will introduce students to the fundamental dynamics that drive project performance, including the rework cycle, feedback effects, and inter-phase "knock-on" effects. Topics covered include dynamic project problems and their causes: the rework cycle and feedback effects, knock-on effects between project phases; modeling the dynamics: feedback effects, schedule pressure and staffing, schedule changes, inter-phase dependencies and precedence; strategic project management: project planning, project preparation, risk management, project adaptation and execution cross project learning; multi-project issues. A simple project model will be created, and used in assignments to illustrate the principles of "strategic project management." Case examples of different applications will be discussed. Prerequisite: SD 550 System Dynamics Foundation: Managing Complexity.

\section{SD 563. Health Care Dynamics}

Why would people go to the doctor more (or less) tomorrow than today? In this course students will explore and learn to simulate behaviors of health care providers, patients, and payers in the U.S. health care system with the goal of better understanding how macro-level patterns emerge from micro-level behaviors. A suite of system dynamics models is developed to explore problems of controlling health care costs and patient utilization. The smaller system dynamics models merge into a larger policy system model that can be used to explore proposed improvements and policy resistance in this sector of the economy. In addition to developing a policy-level model of the health care system, models will be developed on such topics as the spread and control of contagious diseases including SARS, AIDS, seasonal influenza, and pandemic flu, and the dynamics of medical centers of excellence. The objective of the course is to enable the student to develop a system-wide perspective and a framework for health care problem-solving. Prerequisites: SD 550 System Dynamics Foundation: Managing Complexity.

\section{SD 565. Macroeconomic Dynamics}

There are three parts to this course. The first acquaints a student with dynamic macroeconomic data and the stylized facts seen in most macroeconomic systems. Characteristics of the data related to economic growth, economic cycles, and the interactions between economic growth and economic cycles that are seen as particularly important when viewed through the lens of system dynamics will be emphasized. The second acquaints a student with the basics of macroeconomic growth and business cycle theory. This is accomplished by presenting well-known models of economic growth and instability, from both the orthodox and heterodox perspectives, via system dynamics. The third part attempts to enhance a student's ability to build and critique dynamic macroeconomic models by addressing such topics as the translation of difference and differential equation models into their equivalent system dynamics representation, fitting system dynamics models to macroeconomic data, 
and evaluating (formally and informally) a model's validity for the purpose of theory selection. Prerequisites: SD 550 System Dynamics Foundation: Managing Complexity.

\section{Courses which are no longer offered}

\section{SD 555. Psychological Foundations of System Dynamics Modeling}

This course examines the cognitive and social processes underlying the theory and practice of system dynamics. The errors and biases in dynamic decision making that provide the primary rationale for the use of system dynamics modeling will be traced to their root causes in cognitive limitations on perception, attention, and memory. Group processes that influence the outcome of modeler-client interactions and appropriate psychological techniques for eliciting and using mental data to support model building will also be addressed. Additional topics will include the reliability of alternate data sources for modeling, techniques for quantifying soft variables, design issues in group model building, the relative advantages of qualitative and quantitative modeling, and client attitudes toward modeling. Prerequisite: SD550 System Dynamics Foundations: Managing Complexity or permission of the Instructor

\section{SD 590. System Dynamics Modeling for Organizational Change}

The course is based on the following premise: The goal of most SD modeling is to create results and systemic improvement is caused by fundamental shifts in thinking and actions. In short, the successful SD modeling process is a vehicle for organizational change. However, organizations change only because people change and this has significant implications for SD practitioners. The course has a dual focus. One theme is organizational-understanding how people think, the basis of action and the implications for individual and group change. The other focus is the modeling process and how specific techniques can maximize organizational impact. An important part of the course is a "mini" project, during which students apply course concept for real users. Along the way students assess and improve their own ability to facilitate change. Prerequisites: Students are required to have completed SD550, SD560 or SD561 or permission of the Instructor

\section{Appendix C: WPI System Dynamics Teaching Faculty}

\section{Current Faculty}

James K. Doyle. Associate Professor of Psychology and Department Head at WPI (Ph.D., University of Colorado, Boulder, 1992). Areas of expertise: applied social and cognitive psychology, judgment and decision making, risk perception and communication, psychological foundations of system dynamics, and mental models of complex systems.

Robert Eberlein. Co-President, ISEE systems, Inc. (Ph.D., Massachusetts Institute of Technology). Expertise: system dynamics software design and development, model analysis and evaluation, sensitivity analysis, and model optimization. He has been working in the field of System Dynamics for 30 years and has extensive experience teaching and consulting. He recently spent 18 months working in the Health Services and Systems Research department at Duke NUS Graduate medical school. 
He has been active in the System Dynamics Society as President (2004), Secretary, VP Meetings and, currently, VP of Electronic Presence.

Karim Chichakly. Co-President of isee systems and practitioner in the isee Systems Innovation Practice. He has nearly 20 years of system dynamics experience building models primarily in the areas of business strategy, business processes, and public policy, including variations of a national health care model and several infectious disease models. He has a Bachelor's and Master's degrees from Skidmore College, Dartmouth College as well as a Master's in system dynamics from WPI, and a Ph.D. in computer science from University of Vermont.

Andrew Ford. Professor of Environmental Science, School of Earth and Environmental Sciences, Washington State University (Ph.D., Dartmouth College). Areas of expertise: energy modeling, environmental dynamics and policy, and regional planning. In his research he focuses on environmental problems and energy in the western USA. He also teaches a class on climate change.

Michael J. Radzicki. Associate Professor of Economics at WPI (Ph.D., University of Notre Dame, 1985). Professor Radzicki is the creator of WPI's program in system dynamics and co-creator of WPI's program in trading system development. He received his Ph.D. in economics from the University of Notre Dame and his training in system dynamics modeling from the Massachusetts Institute of Technology. In addition, he is a certified Rapid-I Predictive Analytics Analyst. Professor Radzicki's research focuses on predictive analytics, simulation science, and the application of techniques from these areas to problems in economics, finance, and management. He has been invited to speak around the world in venues such as the White House, the Royal Society, the New York Stock Exchange, the United States Departments of Energy, Transportation, and Homeland Security, and Sandia National Laboratories. He has also served on the editorial board of several professional journals and as a consultant to numerous Fortune 500 corporations. In addition to his work in data analysis and simulation, Professor Radzicki is an avid long distance runner, martial artist, golfer, and currency trader. In 2006 he served as president of the System Dynamics Society.

Oleg V. Pavlov. Associate Professor of Economics and System Dynamics at WPI (Ph.D., University of Southern California, 2000). Areas of expertise: system dynamics modeling, computational economics, economics of information systems, and complex economics dynamics. He is past President of the Economics Chapter of the System Dynamics Society and now serves on the Executive Board of the Economics Chapter. He is the Coordinator for the WPI graduate system dynamics program.

Khalid Saeed. Professor of Economics and System Dynamics at WPI (Ph.D., Massachusetts Institute of Technology, 1981). Dr. Saeed was a student of Jay Forrester at MIT and has worked on developing system dynamics models of real-world systems. His insight models have been used to test policies for environmental sustenance, replicate psychology experiments, design innovative organizations, implement developmental agendas, and improve performance of governance systems. He has been teaching the art and science of system dynamics for the past several decades. Dr. Saeed also published on methodological issues. As part of a multidisciplinary team he recently studied the US organ transplant system. This project was supported by HRSA. Dr. Saeed is a former President of the System Dynamics Society (1995) and a recipient of the Jay Forrester Award in System Dynamics.

Jim Thompson. Independent Management Consultant based in Connecticut (Ph.D. University of Strathclyde, Glasgow, Scotland). Dr. Thompson is an experienced system dynamics modeler of health care applications and an enthusiastic instructor with the ample experience of teaching workshops, 
in-class courses and designing online courses. He developed and periodically teaches a Health Dynamics course in the online graduate system dynamics program at WPI. He works with a wide group of stakeholders to resolve issues in health care systems - new pharmaceuticals introductions, evaluating medical technologies, challenges unique to care for frail elderly, control of infectious diseases, and capacity planning. From 2010 through 2012, Dr. Thompson was Head of the Health Systems Design Laboratory at Duke-NUS Graduate Medical School in Singapore, where he focused on health service delivery of treatment and care for persons with age-associated dementia.

John Morecroft. Senior Fellow at London Business School (Ph.D. Massachusetts Institute of Technology). He is an expert in the use of business modeling and simulation for strategy and scenario analysis. He has been a consultant for international organizations including McKinsey and Co., Royal Dutch/Shell, BBC and Mars. Dr. Morecroft is a founding member of the System Dynamics Society. He was an Associate Dean of the Executive MBA Program at London Business School. He also taught at MIT. He is a past Editor of the System Dynamics Review and a member of the Strategic Management Society and INFORMS.

Kim Warren. Owner and Director of Strategy Dynamics Ltd. He is an experienced strategy consultant and teacher who wrote Competitive Strategy Dynamics (Wiley 2002) and Strategic Management Dynamics (Wiley 2008). These two books focus on the strategy dynamics framework which was designed by Dr. Warren as a tool for improving business performance over time. He was teaching strategy dynamics at London Business School from 1990 to 2012. In 2013, he was President of the International System Dynamics Society. Dr. Warren is a recipient of the Jay Forrester award from the International System Dynamics Society. He holds an MBA and Ph.D. from London Business School.

\section{Former Faculty}

Jennifer Kemeny. Independent Consultant. For over 25 years she has pioneered increasingly powerful approaches to create real results - critical insights, renewed motivation and fundamental transformation for her clients. She has worked with Senior Executives in companies of all sizes; from the world's largest institutions to small start-up companies. She has broad for-profit industry experience, but has also devoted considerable time to educational and health care issues. Ms. Kemeny graduated from Dartmouth College in 1975 with a degree in Mathematics/Computer Science. At MIT's Sloan School, from 1980-1986, she pursued doctoral studies in System Dynamics, with a minor in Organization Theory. Ms. Kemeny has an ABD from MIT.

Elise Axelrad, currently a Senior Scientist at HUMPro. Dr. Axelrad was an Assistant Professor at WPI during 2001-2006. Her expertise is in psychology and statistics, with focus on judgment and decision making, problem framing, research design, data analysis, modeling and simulation. She holds degrees from the University of Toronto and she earned a Ph.D. in psychology at Duke University. Prior to WPI, Dr. Axelrad was a Research Associate at University at Albany.

Jim Hines. Consultant at astute SD. Areas of expertise: system dynamics modeling, insight from models, software development, system dynamics consulting methodology. Dr. Hines consulted to public and private-sector organizations in a variety of industries including electronics, software, financial, publishing, shipbuilding, and aerospace. In addition to teaching at WPI, he had taught system dynamics at MIT and at Brown University. He holds a Ph.D. in system dynamics from MIT, an MBA 
in finance and statistics from the University of Chicago, and a BA in English and Anthropology from Amherst College.

James M. Lyneis, currently an Independent Consultant and a Senior Lecturer at MIT, where he teaches System Dynamics and System and Project Management. At WPI, he was a Professor of Practice in System Dynamics. He worked for 25 years in the Business Dynamics Practice of PA Consulting Group (formerly known as Pugh-Roberts Associates). He was General Manager for Pugh-Robert's European office from 1988-1990. At Pugh-Roberts, Dr. Lyneis specialized in the application of system dynamics techniques to business strategy, market analysis, project management, and management training, and worked in the telecommunications, electric utility, aerospace, and financial services industries. Prior to consulting, he was an Assistant Professor at MIT's Sloan School of Management. Dr. Lyneis is the author of the book Corporate Planning and Policy Design: A System Dynamics Approach, as well as numerous journal articles. He has a Ph.D. in Business Administration from the University of Michigan and undergraduate degrees in Electrical Engineering and Industrial Management from MIT.

(C) 2014 by the authors; licensee MDPI, Basel, Switzerland. This article is an open access article distributed under the terms and conditions of the Creative Commons Attribution license (http://creativecommons.org/licenses/by/3.0/). 